\title{
Ameliorative effects of Green Tea Polyphenol Epigallocatechin-3-gallate on chlorpyrifos ovarian toxicity in adult albino rats
}

\author{
Amina A. Farag ${ }^{1^{*}}$, Nashwa H. Abu-Raia ${ }^{2}$, Arigue A. Dessouky ${ }^{3}$, Hanaa E. Bayomy ${ }^{4}$
}

\begin{abstract}
KEYWORDS

Chlorpyrifos (CPF);

Green tea;

Epigallocatechin-3-gallate

(EGCG);

Oxidative stress.

Chlorpyrifos (CPF) can induce ovarian damage and reproductive dysfunction through oxidative stress mechanisms. These can be reversed by antioxidants such as Epigallocatechin-3-gallate (EGCG) in green tea. This study aimed to investigate the toxicity effects of CPF on rat ovaries and the effectiveness of EGCG to protect against these effects. Fifty adult female albino rats were randomly assigned to five equal groups; negative and positive control groups, EGCG-treated group, CPFtreated group and CPF+EGCG-treated group. After four weeks the rat body weight and relative ovarian weight were estimated, and blood samples were collected to assess reproductive hormones (RHs) levels. Evaluation of ovarian oxidative stress indicators malondialdhyde (MDA), nitric oxide (NO), superoxide dismutase (SOD), reduced glutathione (GSH) and catalase (CAT) was performed. Ovarian sections were prepared and examined using the hematoxylin and eosin stain, proliferating cell nuclear antigen, and morphometric study to assess histopathologic changes. CPFtreated rats had significant lower body weight and relative ovarian weight compared to controls $(P<0.001)$ and those treated with CPF+EGCG $(P<0.001)$. CPF induced significant reduction in RHs levels and ovarian SOD, GSH and CAT activities when given alone, which were improved by the combined administration of CPF and EGCG. The levels of ovarian MDA and NO were significantly higher in CPF-treated rats than controls and rats treated with CPF+EGCG. The cellular proliferation in ovarian Graafian follicles was significantly suppressed in CPF-treated animals. Hence CPF can induce oxidative damage in rat ovaries, EGCG, a natural potent antioxidant, can be useful against the CPF toxicity effects in ovaries.
\end{abstract}

\section{Introduction}

Chlorpyrifos (CPF) (0,0-diethyl 0-(3,5,6trichloro-2-pyridinyl)-phosphorothioate), is an organophosphate (OP) pest controller that was

\footnotetext{
(1) Department of Forensic Medicine and Clinical Toxicology, Faculty of Medicine, Benha University, Egypt

(2) Department of Pharmacology, Faculty of Medicine, Benha University, Egypt

(3) Department of Histology and Cell Biology, Faculty of Medicine, Zagazig University, Egypt

(4) Department of Public Health \& Community Medicine, Faculty of Medicine, Benha University, Egypt

* Corresponding author:

Dr. Amina A. Farag, MD: Department of Forensic Medicine and Clinical Toxicology,Faculty of Medicine, Benha University, Egypt.

Tel:+201015906446

Email: amina.farag@fmed.bu.edu.eg
}

introduced in 1965 as a foliage pesticide to protect significant crops (Fang et al., 2008). CPF has been widely used in developing countries to guard against plant and domestic pests such as leafhopper, cutworms, leaf folder, corn rootworms, gall midge, cockroaches, flies, grubs, termites, flea beetles, lice, fire ants, and mosquitos. It has been used to protect plants used as human food such as rice, cereals, fruits and vegetables, industrial crops as cotton and ornamental plants. Preconstruction application of CPF was used for termite control (Yadav et al., 2016). 
However, CPF was found to be toxic to humans and animals and has a long environmental persistence (Sharma et al., 2017). Exposure to CPF is commonly through ingestions of contaminated food and occupational exposure via contact and inhalational routes. CPF is rapidly absorbed from the skin and intestine (Poet et al., 2014).

CPF has been linked to several toxicity effects in humans and animals. CPF, as an organophosphate, is an anticholinesterase and can lead to the accumulation of acetylcholine and induce neurotoxic manifestations (Anirudhan et al., 2013). Animal studies showed that CPF was associated with histopathological damage of internal organs, disruption of gut microbiome, embryotoxicity, teratogenicity, genotoxicity and immunotoxicity (Wang et al., 2019). In humans, chronic exposure to CPF was charged of adverse health effects including chronic degenerative diseases and cancers (Hernandez et al., 2013). CPF can influence glucose and lipid metabolism and lead to obesity, dyslipidemia and type-2 diabetes mellitus. $\mathrm{CPF}$ was suggested to induce changes in reproductive hormones $(\mathrm{RH})$ levels in animals (Li et al., 2019).

CPF was claimed to cause irregular estrous cycle, abnormal growth of breast cells and primordial follicles in ovary of rats (Kamalesh et al., 2014).

Changes in reproductive functions were used as an indicator for pesticide toxicity. Females were found to be more sensitive to the toxicity effects of pesticides (Attia et al., 2012).

In humans, $\mathrm{CPF}$ is metabolized in liver by cytochrome $\mathrm{P} 450$ and its metabolites are excreted in urine. CPF poisoning can be diagnosed by the detection of its metabolites diethylphosphate (DEP), diethylphosphorothioate (DETP), and 3,5,6-trichloro-2- pyridinol (TCP) in serum and urine samples (Hodgson and Rose, 2008).

CPF produce its toxicity effects by two main mechanisms; oxidative stress and lipid peroxidation. In oxidative stress endogenous antioxidants such as catalase, superoxide dismutase, glutathione S-transferase fail to oppose reactive oxygen species (ROS) and other free radicals generated by CPF. These free radicals interact with carbohydrates, lipids, and DNA leading to damage of the brain and reproductive tissues (Attia et al., 2012). Lipid peroxidation can lead to damage of the brain as well as ovarian tissues (Nishi and Hundal, 2013).

Oxidative stress is due to failure of endogenous antioxidants to counteract the effect of free radicals generated by CPF. So, it was suggested that introduction of antioxidants such as green tea would protect against the toxic effects of CPF by preventing the oxidative stress (Pohl and Kong Thoo Lin, 2018).

Green tea (GT), Camellia sinensis (Family: Theaceae), is one of the most commonly used beverage all over the world, and is considered the most potent natural antioxidant due to its ingredient Epigallocatechin-3-gallate (EGCG), which contains eight free $\mathrm{OH}$ - group (Rains et al., 2011). Green tea was presented as a major preventive factor against chronic human diseases. Its main preventive affects are due to antioxidative action, induction of detoxifying enzymes, regulation of cell growth, development and apoptosis, and enhancement of intestinal bacterial flora (Weisburger and Chung, 2002).

EGCG protect against oxidation of lowdensity lipoprotein and prevent DNA and cellular damage (Takagaki et al., 2011). In addition, EGCG has anti-inflammatory (Gao et al., 2016), antivirus (Ohno et al., 2013) and anti-cancer effects (Min and Kwon, 2014). It 
has been found to be useful against ulcerative colitis (Bitzer et al., 2016) and autoimmune diseases (Wu et al., 2012). EGCG is a potent antioxidant that is 30 times more potent than vitamin $C$ and vitamin E (Intra and Kuo, 2007) and can be used as a dietary supplement, which is easily administered and highly acceptable.

The study aimed to investigate the protective effect of Epigallocatechin-3-gallate in green tea on the toxic effects of CPF on rat ovaries.

\section{Material \& Methods}

\section{Chemicals}

1- Chlorpyrifos :CPF technical grade (98\%) was purchased from El-Gomhouria Company for Trading Chemicals and Medical Appliances., Egypt.

2- Epigallocatechin-3-gallate (EGCG) as a powder of purity $\pm 95 \%$ was purchased from Sigma-Aldrich, USA (CAS Number 989-51-5).

3 - Corn oil as a liquid of purity $\pm 99 \%$ was purchased from Sigma-Aldrich, USA (CAS number 8001-30-7).

4-Nuclear Antigen (PCNA): PCNA monoclonal antibody (clone pc 10) was purchased from Lab Vision USA by Medico Trade Company, Giza, Egypt.

5- All kits used for different oxidative/antioxidative markers malondialdehyde (MDA), nitric oxide (NO); glutathione (GSH); and superoxide dismutase (SOD), catalase (CAT) were purchased from Laboratory BioDiagnostics Co., Giza, Egypt.

\section{Animals}

The experimental protocol of the study was designed according to the rules approved by the Ethical Committee of the Faculty of
Medicine, Benha University, Egypt. Fifty adult female albino rats of average weight, weighing 180-200 gm., aged 8-10 weeks, were purchased from the Experimental Animal Breeding Farm, (Helwan-Cairo). Animals were left for one week for proper acclimatization to the animal house conditions at the Pharmacology Department, Faculty of Medicine, Benha University, to ascertain their physical wellbeing, and to exclude any diseased animals. All animals were received the same diet (wheat, bread \& milk) on a schedule of 12 hours of light and 12 hours of dark. The time of dose administration was fixed for all animals at 12 P.M.

\section{Experimental design}

The animals were randomly assigned to five equal groups (10 rats each):

Group I (negative control group): Each animal received physiological saline via intragastric tube for 4 weeks.

Group II (positive control group): Each animal received $1 \mathrm{ml} /$ day of corn oil via intragastric tube for 4 weeks.

Group III (EGCG group): was treated with EGCG $(20 \mathrm{mg} / \mathrm{kg}$ body weight $)$, administered once a day for 4 weeks via intragastric tube, which was dissolved in physiological saline. The EGCG dose used in the present study was previously employed with no harmful effects on animals (You et al., 2014).

Group IV (CPF group): Each animal received $\mathrm{CPF}$ in corn oil through intragastric tube at a dose $5.4 \mathrm{mg} / \mathrm{kg} /$ day $[1 / 25$ of the calculated median lethal dose (LD50)] for 4 weeks. This dose was enough to induce biochemical changes without morbidity (Mansour and Mossa, 2009). 
Group V (CPF + EGCG group): Each animal was given both EGCG (at the same dose of group III) and CPF (at the same dose of group IV), through intragastric tube for 4 weeks.

All animals were sacrificed 24 hours after the last administrated dose by ether inhalation, dissected and the ovaries were removed for histological and immunohistochemical studies.

\section{Sample collection and storage}

Animals were anesthetized by ether, the abdominal cavity was opened, and blood samples were collected from their hearts by 5 $\mathrm{ml}$ syringes. Blood samples were kept in clean tubes without anticoagulants at $37^{\circ} \mathrm{C}$ incubator for 15 minutes. After centrifugation of clotted blood, serum samples were put in special tubes, covered by parafilm, labelled and kept frozen for three days to be tested later for the reproductive hormones (Picard et al., 2008).

\section{Methods:}

\section{1-Body weight and relative ovary weight}

The weights of rats were recorded before and after the treatment periods. The ovary was collected, weighed, and the relative weight of the ovary was calculated as a proportion of each animal's body weight.

\section{2-Biochemical analysis}

\section{Assessment of serum hormonal assay}

Serum estrogen (estradiol E2), progesterone $(\mathrm{Pg}), \quad$ follicle-stimulating hormone $(\mathrm{FSH})$, luteinizing hormone (LH) levels were estimated using Enzyme Linked Fluorescence Assay (Anckaert et al., 2002), with the commercial kits VIDAS (BIOMERIEUX Company, France) by VIDAS apparatus (BIOMERIEUX Company, France).
Assessment of oxidative stress indicators in ovarian tissues

The oxidative stress parameters evaluated were indicators of lipid peroxidation malondialdhyde (MDA) and nitric oxide (NO) and antioxidants: superoxide dismutase (SOD), reduced glutathione (GSH) and catalase (CAT). MDA was evaluated by measuring the colour emitted from the interaction between MDA and thiobarbituric using a spectrophotometer at $535 \mathrm{~nm}$ against a blank. A standard curve by 1,1,3,3tetramethoxypropane was developed and the MDA concentration was expressed as $\mathrm{nmol} / \mathrm{g}$ tissue (Mihara and Uchiyama, 1978). The ovarian NO was estimated by using copperized cadmium to reduce nitrate to nitrite and measuring the total nitrite by the Griess reaction (the reaction of nitrite with a mixture of naphthylethylenediamine and sulphanilamide) (Sastry et al., 2002). SOD activity was evaluated using the method developed by Marklund and Marklund (1974) that is based on the inhibition of the autoxidation of pyrogallol by SOD. The SOD enzyme activity was expressed as $\mathrm{U} / \mathrm{g}$ tissue, where one unit is the amount of the enzyme that inhibited the rate of pyrogallol autoxidation by $50 \%$. Catalase activity was determined by the interaction of $20 \mu \mathrm{L}$ of the sample with a mixture of $1800 \mu \mathrm{L}$ of $50 \mathrm{mM}$ phosphate buffer (pH 7.0), $180 \mu \mathrm{L}$ of $300 \mathrm{mM}$ $\mathrm{H} 2 \mathrm{O} 2$. The rate of $\mathrm{H} 2 \mathrm{O} 2$ clearance was monitored by a UV-Visible spectrophotometer at $240 \mathrm{~nm}$ for $2 \mathrm{~min}$ (10 $\mathrm{sec}$ intervals). The activity of catalase was then expressed as $\mu \mathrm{mol} \mathrm{H} 2 \mathrm{O} 2$ consumed $/ \mathrm{min} / \mathrm{mg}$ protein (Clairborne, 1995). GSH level was estimated using the method described by Jollow et al. (1974). An equal volume of the sample and $4 \%$ sulfosalicylic acid are mixed and centrifuged at $10,000 \mathrm{x} \mathrm{g}$ for $15 \mathrm{~min}$ at $4^{\circ} \mathrm{C}$. Then, $50 \mu \mathrm{L}$ of the supernatants was added to DTNB (10 mM, $4.5 \mathrm{~mL})$, and the absorbance was measured at $412 \mathrm{~nm}$. GSH levels were measured in $\mu \mathrm{mol} / \mathrm{mg}$ protein. 


\section{3- Histological and Immunohistochemical Study}

Immediately after the animals were sacrificed, their right and left ovaries were dissected, fixed in $10 \%$ formol saline for $24-48$ hours, dehydrated in ascending grades of alcohol, cleared in xylene and embedded in paraffin. Paraffin blocks were cut at $5-7 \mu \mathrm{m}$ thickness, using Leica rotator microtome (Germany). Sections were examined using the following stains: Hematoxylin and Eosin stain (Kiernan, 2001).

Immunohistochemical staining using the avidin-biotin peroxidase complex technique. Sections were counterstained with Meyer's hematoxylin (Bancroi and Gamble, 2002) for detection of:

Proliferating Cell Nuclear Antigen (PCNA):

PCNA is an auxillary protein of DNApolymerase enzymes, necessary for DNA synthesis and is used as a standard marker in proliferating cells (Kerr et al., 2006). PCNA antibody is a mouse monoclonal antibody PC 10 (Novocastra, Milton, Keynes, USA). PCNA positive cells show brown nuclear deposits.

-Positive tissue control for PCNA: Human tonsil biopsies showed +ve immunostaining in the form of brown nuclear reaction for PCNA.

-Negative control for PCNA: Additional specimens of the ovary were processed in the same sequence but the primary antibody was not added and instead, PBS was added in this step. Omission of the primary antibody gave no staining reaction.

\section{5-Morphometric Study}

This was carried out using a Leica Qwin 500 LTD image analysis computer system, (Cambridge, UK). For each group, five slides of five different specimens were examined. From each slide, ten non-overlapping fields were measured. The following parameters were evaluated:
- Mean area percent of positive immunoreactivity for PCNA. It was measured in immune-stained sections using the colour detect menu, in relation to a standard measuring frame, at a magnification of X400.

- Mean areas of positive immunoreactivity for PCNA were masked by a blue binary colour.

\section{Statistical analysis}

Collected data were summarized as mean \pm Standard Error of the Mean (SEM) and range. Shapiro-Wilk $\mathrm{W}$ test for normal data was used to test the distribution of data. Comparisons between the different study groups were carried out the One-Way Analysis of Variance (ANOVA; F) for normally distributed data and the Kruskal Wallis (KW) test for non-parametric data. These were followed by post-hock tests using the Bonferroni method to detect difference in pairs. Changes in the rat body weight after treatment as compared to before treatment were tested using the paired t-test. Statistical significance was considered at $\mathrm{P}<0.05$. All statistical analysis was carried out using STATA/SE version 11.2 for Windows (STATA Corporation, College Station, Texas) (STATA Corp, 2009).

\section{Results}

The results of both negative and positive control groups did not show any statistically significant differences, so, the data obtained for both groups were expressed in the figures and tables as one group "control".

Table (1) showed no significant differences in body weight between the different groups at the beginning of the study. There was a significant increase in body weight in all the study groups at the end of the study except for the CPF-treated group, which had a significantly reduced body weight compared to before treatment $(\mathrm{P}=0.0026)$. 
Table (1): Rats' body weight in gram before and after treatment.

\begin{tabular}{|c|c|c|c|c|c|c|c|}
\hline & \multicolumn{5}{|c|}{$\begin{array}{c}\text { Body weight (gm) } \\
\text { Mean } \pm \text { SEM (range) }\end{array}$} & \multirow[b]{2}{*}{$\mathbf{F}$} & \multirow[b]{2}{*}{$\mathbf{P}$} \\
\hline & $\begin{array}{c}\text { Control } \\
\text { (saline- } \\
\text { treated } \\
\text { group) } \\
(\text { no. }=10) \\
\end{array}$ & $\begin{array}{l}\text { Control (corn } \\
\text { oil-treated } \\
\text { group) } \\
\text { (no.=10) }\end{array}$ & $\begin{array}{l}\text { EGCG- } \\
\text { treated } \\
\text { group } \\
(\text { no. }=10)\end{array}$ & $\begin{array}{l}\text { CPF- } \\
\text { treated } \\
\text { group } \\
(\text { no.=10) }\end{array}$ & $\begin{array}{c}\text { CPF+EGCG } \\
\text {-treated } \\
\text { group } \\
(\text { no. }=10)\end{array}$ & & \\
\hline $\begin{array}{l}\text { Before } \\
\text { treatment }\end{array}$ & $\begin{array}{c}199.7 \pm 2.69 \\
(186-215) \\
\end{array}$ & $\begin{array}{c}199.5 \pm 2.81 \\
(185-216)\end{array}$ & $\begin{array}{c}191.40 \pm 2.15 \\
(183-202) \\
\end{array}$ & $\begin{array}{c}199.5 \pm 3.45 \\
(182-213) \\
\end{array}$ & $\begin{array}{c}192.5 \pm 2.23 \\
(182-205) \\
\end{array}$ & 2.39 & $\begin{array}{l}0.0 \\
64 \\
\end{array}$ \\
\hline $\begin{array}{c}\text { After } \\
\text { treatment }\end{array}$ & $\begin{array}{c}209.2 \pm 2.80 \\
(195-223) \\
\end{array}$ & $\begin{array}{c}208.4 \pm 2.93 \\
(194-224) \\
\end{array}$ & $\begin{array}{l}199 \pm 3.26 \\
(183-212) \\
\end{array}$ & $\begin{array}{c}196.7 \pm 3.15 \\
(183-210) \\
\end{array}$ & $\begin{array}{c}202.4 \pm 3.40 \\
(185-217) \\
\end{array}$ & 3.18 & $\begin{array}{l}0.0 \\
22 \\
\end{array}$ \\
\hline $\mathrm{T}$ & 16.88 & 19.42 & 4.86 & 4.12 & 6.66 & & \\
\hline $\mathrm{P}$ & $<0.001$ & $<0.001$ & 0.0009 & 0.0026 & 0.0001 & & \\
\hline
\end{tabular}

SEM: Standard Error of the Mean; F: One-Way Analysis of Variance (ANOVA); P: Probability; t: Paired t-test; EGCG: Epigallocatechin-3-gallate; CPF: Chlorpyrifos

Figure (1) showed significant variations in the relative ovarian weight between the studied groups $(\mathrm{P}=0.0009)$. CPF-treated group had the least relative ovarian weight
$(0.017 \pm 0.003 \mathrm{mg} / 100 \mathrm{~g}$ body weight) followed by $\mathrm{CPF}+\mathrm{EGCG}$-treated group $(0.023 \pm 0.003$ $\mathrm{mg} / 100 \mathrm{~g}$ body weight).

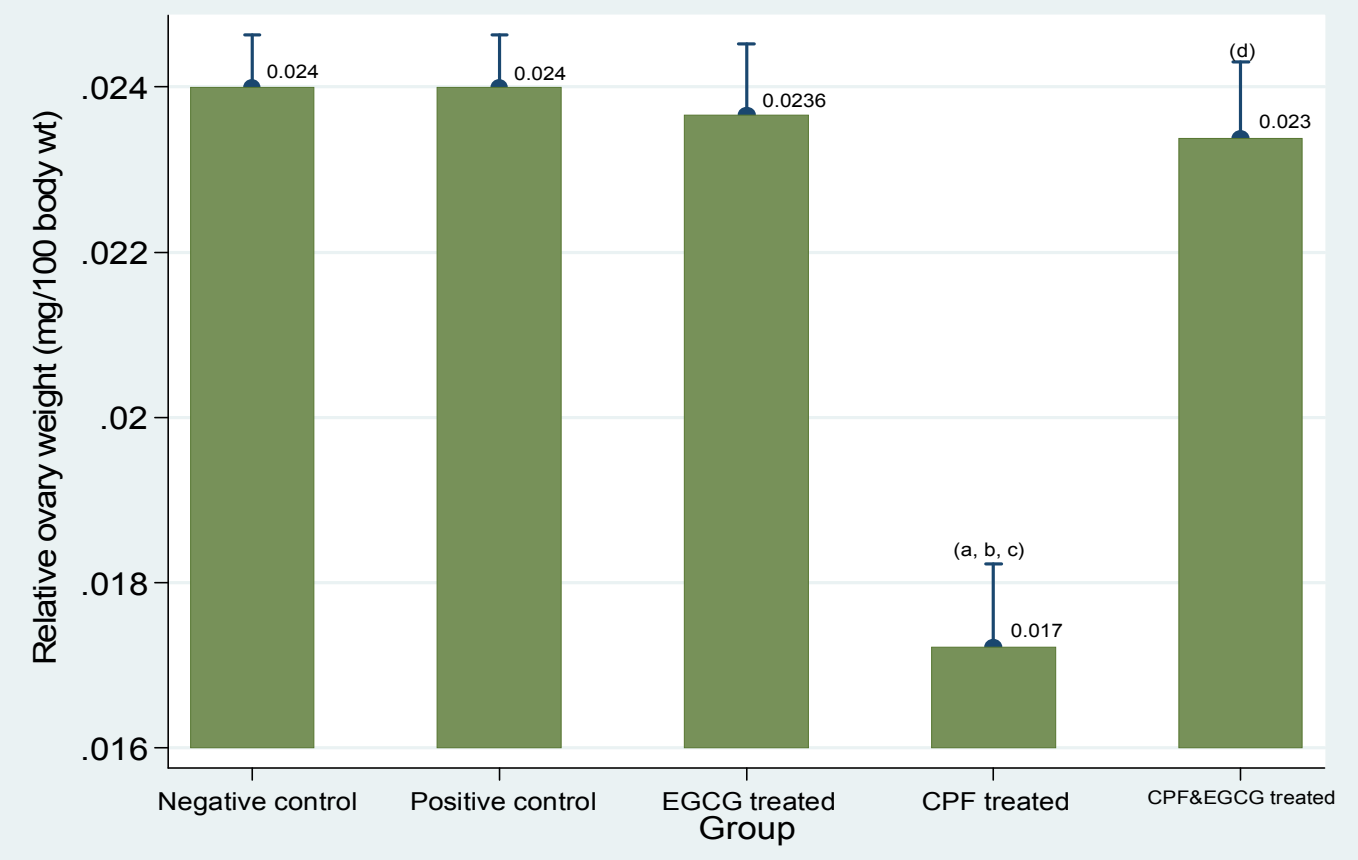

Fig. (1): Mean and Standard Error of the Mean (SEM) of the relative ovary weight between the studied groups. 


\section{Assessment of serum hormonal assay}

EGCG: Epigallocatechin-3-gallate; CPF: Chlorpyrifos; a: significant difference compared to the negative control group; $b$ : significant difference compared to positive control group; c: significant difference compared to EGCG treated group; d: significant difference compared to $\mathrm{CPF}$ treated group; $\mathrm{P}<0.001$; Kruskal Wallis test and post-hock using the Bonferroni method were used.

The CPF-treated group had lower levels of progesterone, oestrogen, $\mathrm{FSH}$ and $\mathrm{LH}$ compared to control and EGCG-treated groups $(\mathrm{P}<0.001)$. However, the levels of reproductive hormones were higher in the CPF+EGCG-treated than in the CPF-treated group. These differences were statistically significant $(\mathrm{P}<0.001)$ for progesterone, oestrogen and FSH (Figure 2).

Assessment of ovarian tissue oxidative stress/antioxidant biomarkers

Figure 3 showed the indicators of ovarian oxidative stress among the studied groups. CPF-treated group had the highest levels of MDA and NO $(\mathrm{P}<0.001)$. The levels of MDA and NO were significantly lower in $\mathrm{CPF}+\mathrm{EGCG}$-treated group than in CPF-treated group $(\mathrm{P}<0.001)$. Administration of $\mathrm{CPF}$ caused significant reduction in ovarian SOD, CAT and GSH levels compared to the control group, EGCG-treated group and CPF+EGCGtreated group $(\mathrm{P}<0.001)$.
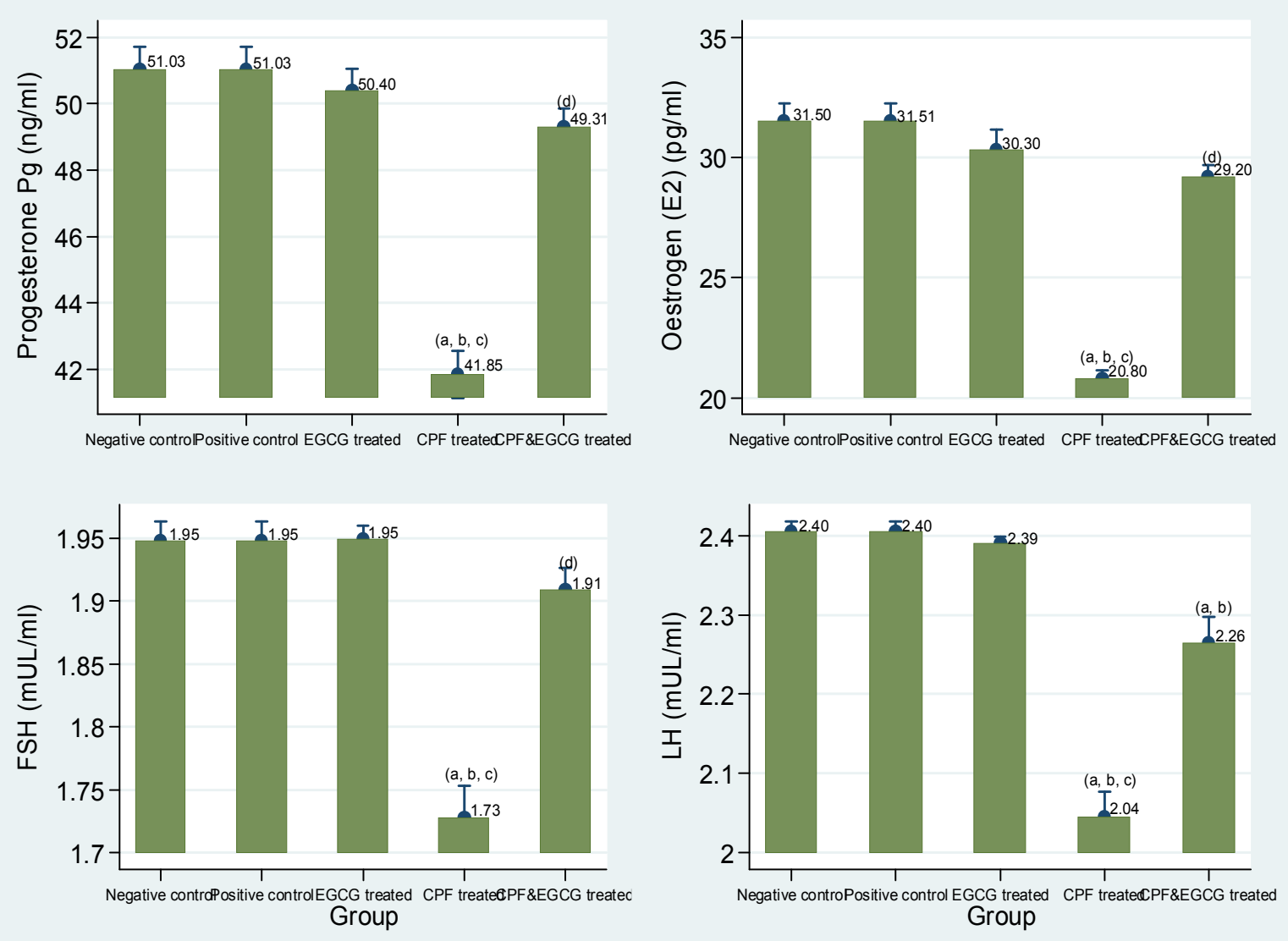

Fig. (2): Mean and Standard Error of the Mean (SEM) of reproductive hormones levels between the studied groups. 
EGCG: Epigallocatechin-3-gallate; CPF: Chlorpyrifos; FSH: Follicle Stimulating Hormone; LH: Luteinizing Hormone; a: significant difference compared to the negative control group; b: significant difference compared to positive control group; c: significant difference compared to EGCG treated group; d: significant difference compared to CPF treated group; $\mathrm{P}<0.001$; Kruskal Wallis test and post-hock using the Bonferroni method were used.

Examination of Hematoxylin and Eosin and PCNA immune sections of the control groups showed non-significant differences.
Thus, sections of group I were used to represent the control group.

Examination of sections of the control group revealed mature Graafian follicles containing large round oocytes with pale staining cytoplasm and central nuclei surrounded by well-defined acidophilic zona pellucida. The oocytes were surrounded by the corona radiata and attached to the walls of the follicles through the cumulus oophorus. The follicular walls were formed of multiple layers of tightly packed granulosa cells. The antrum appeared large and full of acidophilic liquor folliculi (Figure 4A).

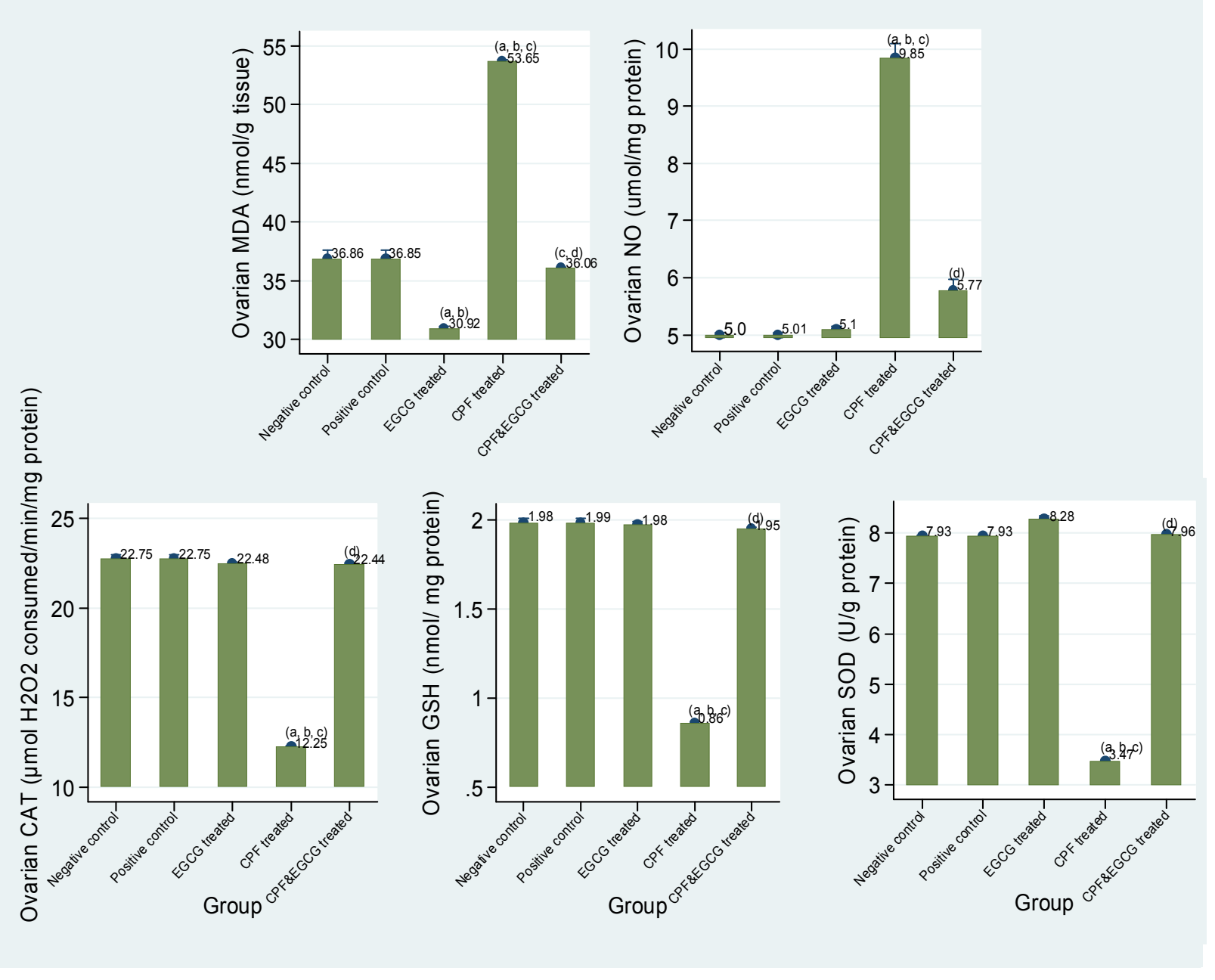

Fig. (3): Mean and Standard Error of the Mean (SEM) of ovarian oxidative stress indicators between the studied groups. 
EGCG: Epigallocatechin-3-gallate; CPF: Chlorpyrifos; MDA: Malondialdhyde; NO: Nitric Oxide; SOD: Superoxide Dismutase; CAT: Catalase; GSH: reduced Glutathione; a: significant difference compared to the control group; b: significant difference compared to EGCG treated group; c: significant difference compared to $\mathrm{CPF}$ treated group. $\mathrm{P}<0.001$; Kruskal Wallis test and post-hock using the Bonferroni method were used.

\section{Hematoxylin and Eosin}

The mature Graafian follicles of the EGCG treated group had large ovoid oocytes surrounded by the corona radiata and attached to the follicular wall by the cumulus oophorus. The walls of the follicles were formed of tightly packed granulosa cells (Figure 4B).

CPF treated group induced degenerative changes in the Graafian follicle in the form of distortion of the oocytes with prominent vacuoles in the cytoplasm and irregular corona radiata. The granulosa cells of the follicular walls appeared shrunken and darkly stained with wide spaces between them and separation from the underlying theca layer (Figure 4C).

Rats receiving $\mathrm{CPF}+\mathrm{EGCG}$ showed some improvements in the histological structure of the follicles. The oocytes were large, rounded and surrounded by the corona radiata. The granulose cell layer appeared wider with spaces between the cells but not separated from the underlying theca layer (Figure 4D).

\section{Immunohistochemical results}

To assess the proliferation of granulosa cells after EGCG administration, PCNA immunostaining was used and gave nuclear reaction in granulosa cells. PCNA expressed moderate positive immune expression in granulosa cells of control group \& EGCG group but with more reaction in group EGCG (Figures 5 A \& B). PCNA expression was much more pronounced in $\mathrm{CPF}+\mathrm{EGCG}$ group (Figure $5 \mathrm{D}$ ), while the expression of PCNA was minimal in CPF group (Figure $5 \mathrm{C}$ ).

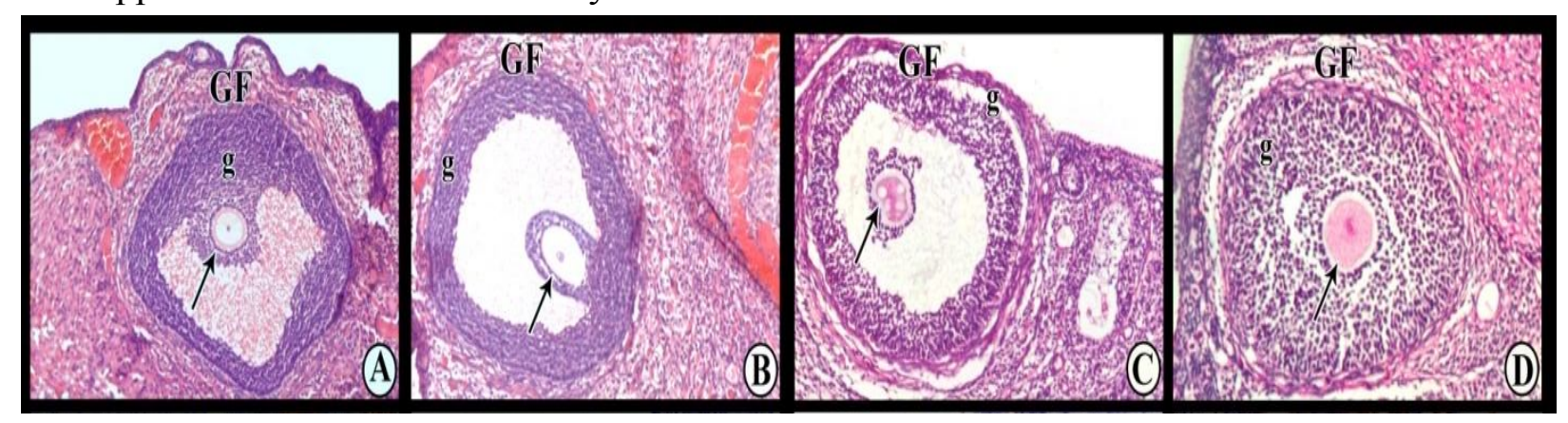

Fig. (4): A photomicrograph of H\&E stained sections showing the mature Graafian follicles of the different experimental groups (A-D): (A) Control group: showing a large round oocyte with pale staining cytoplasm and nucleus surrounded by a well-defined acidophilic zona pellucida (arrow). The oocyte is surrounded by the corona radiata and attached to the wall of the follicle by the cumulus oophorus. Multiple layers of closely packed granulosa cells (g) form the follicular wall. (B) EGCG group: large ovoid oocyte surrounded by the corona radiata and attached to the follicular wall by the cumulus oophorus. The granulosa cells $(\mathrm{g})$ appear tightly packed. (C) CPF group: distorted acidophilic oocyte with multiple vacuoles in its cytoplasm (arrow) surrounded by an irregular corona radiate. The granulosa cells (g) appear shrunken and darkly stained with wide spaces between them and separation from the underlying theca layer. (D) CPF+ EGCG group: Large rounded oocyte (arrow) surrounded by the corona radiata. The granulose cell layer (g) appears wider with spaces between the cells and no separation from the theca layer ( $\mathrm{GF}=$ Graafian follicle) $(\mathbf{H} \& \mathbf{E} \mathbf{x 4 0 0})$. 


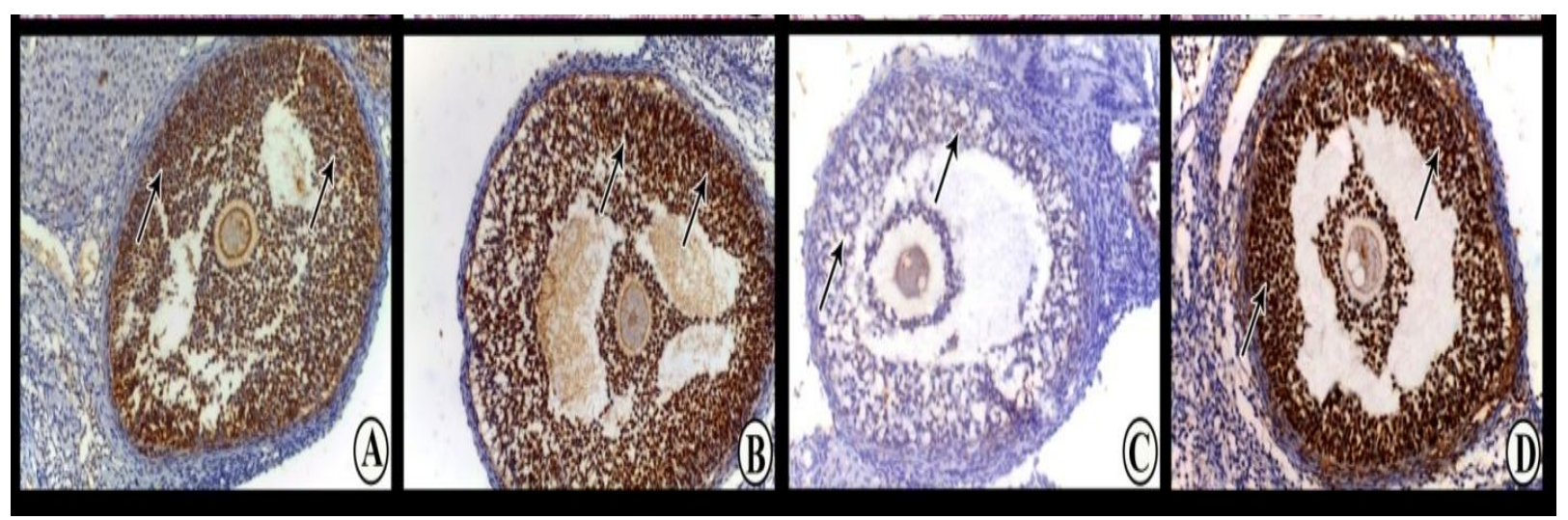

Fig. (5): A photomicrograph of PCNA immune stained sections showing the mature Graafian follicles of the different experimental groups (A-D): (A) Control group: showing a moderate nuclear reaction in most of the granulosa cells (arrows). (B) EGCG group: showing an intense nuclear reaction in some of the granulosa cells (arrows). (C) CPF group: showing a mild nuclear reaction in few of the granulosa cells (arrows). (D) CPF+ EGCG group: showing an intense nuclear reaction in all of the granulosa cells (arrows) (Immunostaining for PCNA with $\mathrm{H}$ stain as a counter stain $\times 400$ ).

Comparisons of proliferating cells per unit area in Graafian ovarian follicles in the different studied groups (mean \pm SEM) are shown in Figure 6. CPF-treated rats had significantly lower values compared to controls $\quad(\mathrm{P}<0.001)$. While, $\mathrm{CPF}+\mathrm{EGCG}$ treated group was comparable to control group $(\mathrm{P}>0.05)$ and significantly higher than rats treated with CPF alone $(\mathrm{P}<0.001)$.

\section{Discussion}

CPF is a widely used organophosphate insecticide, which has been linked to many adverse health effects such as neurotoxicity, hormonal disruption, molecular and cellular damage of the brain and reproductive tissues.
The toxicity effects of CPF are brought about mainly by oxidative stress and lipid peroxidation ( $\mathrm{Li}$ et al., 2019).

This experimental study was conducted to investigate the protective effect of Epigallocatechin-3-gallate in green tea on the toxic effects of CPF on rat ovaries. Our results revealed that $\mathrm{CPF}$ interfered with normal weight gain in treated rats and induced significant suppression of reproductive hormones and ovarian damage through enhanced lipid peroxidation and oxidative stress. In addition, CPF-treated rats showed marked histopathological changes in ovarian tissues. The administration of EGCG succeeded to ameliorate these toxicity effects of CPF. 


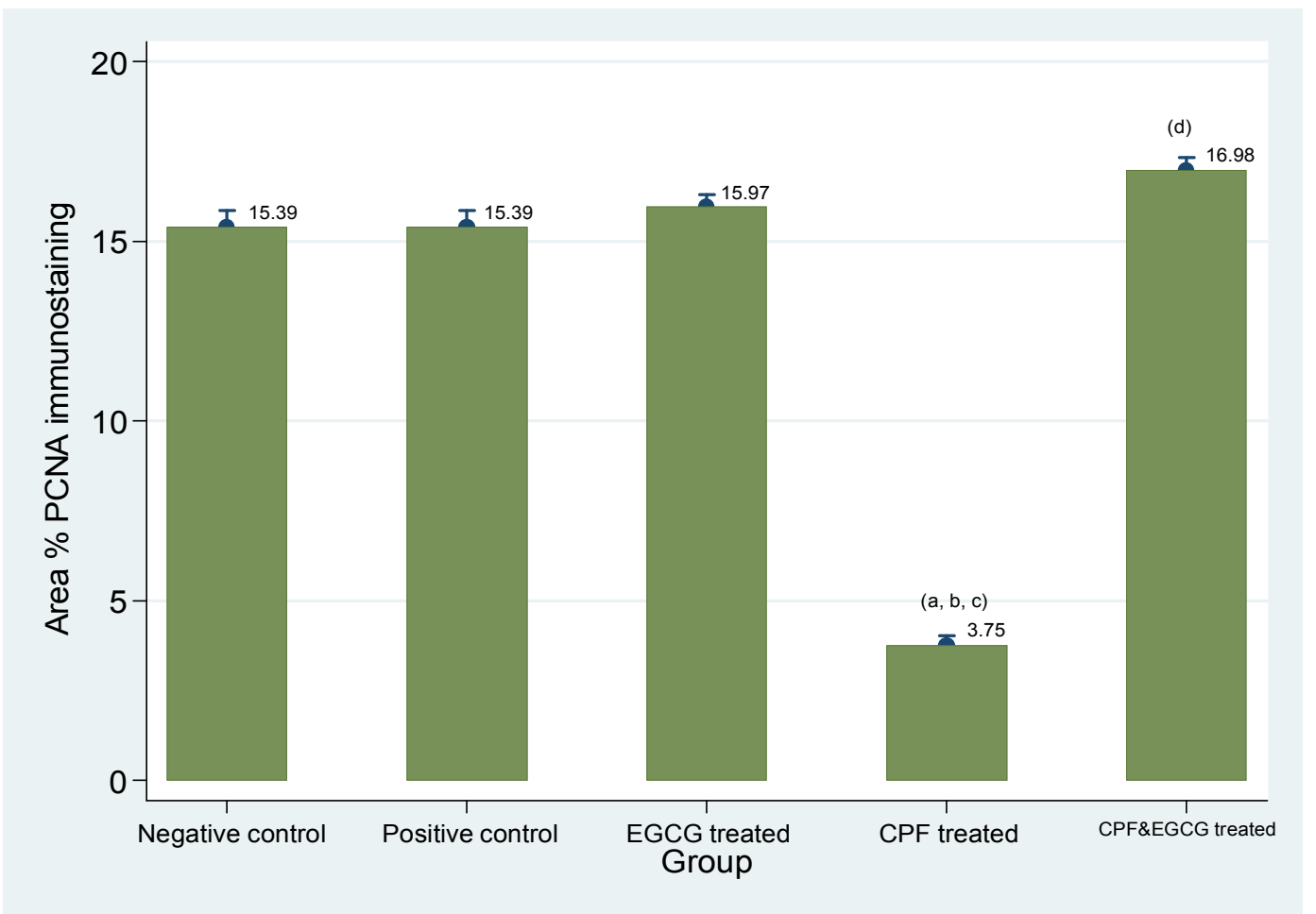

Fig. (6): Mean and Standard Error of the Mean (SEM) of Proliferating Cell Nuclear Antigen (PCNA) immunostaining in the different experimental groups

EGCG: Epigallocatechin-3-gallate; $\mathrm{CPF}$ : Chlorpyrifos; a: significant difference compared to the negative control group; b: significant difference compared to positive control; c: significant difference compared to EGCG treated group; d: significant difference compared to $\mathrm{CPF}$ treated group; $\mathrm{P}<0.001$; Kruskal Wallis test and post-hock using the Bonferroni method were used

Chronic exposure to CPF has been linked to changing body weight. In the present study CPF-treated rats had significantly lower body weight and relative ovarian weight than the non-treated groups and those treated with CPF+EGCG. Moreover, CPF-treated rats had lower body weight at the end of the study, after four weeks, than at the beginning of the study. Correspondingly, CPF-treated animals $(6.75 \mathrm{mg} / \mathrm{kg})$ showed significant reduction in body weight $(-7.32 \%, \mathrm{P}<0.05)$ and relative ovarian weight $(-13.74 \%, \mathrm{P}<0.05)$ compared to animals treated with Pistacia Lentiscuc L
(PLO) ( $2 \mathrm{ml} / \mathrm{kg}$ ) for 30 days (Chebab et al., 2017). Similarly, CPF caused significant decrease in body weight, relative ovarian weight and thyroid weight in rats (Shady and Noor El-Deen, 2010; Das et al., 2014). In addition, rats treated with CPF $(5 \mathrm{mg} / \mathrm{kg})$ had significant weight loss after 35 days of treatment. In line with our results, weight loss was induced by CPF and this was explained by oxidative stress and damage of fat and protein (Zhang et al., 2019). In addition, the reduced body weight induced by CPF can be due to direct cellular effects or effects on higher centres in the brain that govern food and water intake and hormonal function (Mavedati et al., 2015). The reduced ovarian weight induced by CPF was explained by the increased release of adrenocorticotropic hormone (ACTH) which causes protein damage in ovaries (Johari et al., 2010).

However, there were no significant weight change after treatment with CPF (0.1 
and $2.5 \mathrm{mg} / \mathrm{kg} /$ day for 8 weeks) (Nishi and Hundal, 2013). Moreover, it was found that CPF increased perinephric pads of fat (Mansour and Mossa, 2009; Liang et al., 2019).

In the current study, the administration of CPF was associated with significant reduction in the levels of progesterone $(\mathrm{Pg})$, estrogen (E2), FSH and LH. These were improved in rats treated with EGCG in addition to CPF. In agreement with these results, a significant reduction in $\mathrm{Pg}$ and E2 was also noticed in CPF-treated rats at doses of 5.4 and $8.1 \mathrm{mg} / \mathrm{kg}$ body weight/day (Das et al., 2014) and environmental doses 0.01 and 1 $\mathrm{mg} / \mathrm{kg}$ body weight/day (Ventura et al., 2016). Correspondingly, the investigations of the effects of CPF and curcumin on FSH levels in mice revealed a progressive decrease in FSH levels with increased duration (after two and three weeks) and dose (CPF $10 \mathrm{mg} / \mathrm{kg}$ body weight, and $20 \mathrm{mg} / \mathrm{kg}$ body weight) of CPF treatment (Madhavi and Sai Saraswathi, 2011). Similarly, a significant dose-dependent reduction in FSH, LH and oestrogen CPFtreated rats with three different concentration of CPF $(0.2 \%, 0.4 \%$ and $0.8 \%)$ (Iheanacho et al., 2020). In addition, CPF-treated rats had significantly lower levels of LH $(-49.13 \%$, $\mathrm{P}<0.01), \mathrm{Pg}(-24.56 \%, \mathrm{P}<0.01)$ and E2 ($28.84 \%, \mathrm{P}<0.01)$ compared to controls and rats treated with $\mathrm{CPF}+\mathrm{PLO}$ (Chebab et al., 2017).

Moreover, Das et al. (2014) noticed a failure in the hypothalamo-pituitary-gonadal feedback mechanisms in response to the drop in Pg and E2 levels as a result of CPFmediated damage of the ovaries, which was explained by the toxicity effects of CPF on the pituitary gland and hypothalamus by AChE inhibition. In another study, it was also suggested that $\mathrm{CPF}$ inhibits the $\mathrm{RH}$ genes expression (Ventura et al., 2016). An oxidative damage induced by CPF on the ovaries (Nishi and Hundal, 2013) and the anterior pituitary have been suggested (Muftau et al., 2014).

However, Das et al. (2017) reported a significant dose-dependent reduction in estradiol levels in CPF-treated rats after 30 days without a significant reduction in progesterone levels at all CPF treatment doses $(5.4 \mathrm{mg} / \mathrm{kg}$ body weight/day and $8.1 \mathrm{mg} / \mathrm{kg}$ body weight/day). Non-significant changes in progesterone levels in rats treated with three different CPF concentrations were also reported (Iheanacho et al., 2020).

In this study indicators for ovarian lipid peroxidation (MDA and NO) were significantly increased by $\mathrm{CPF}$ and these changes were lessened in $\mathrm{CPF}+\mathrm{EGCG}$-treated rats. $\mathrm{CPF}$ induced significant reduction in ovarian CAT, GSH and SOD. However, administration of EGCG could protect the rats from the oxidative stress induced by CPF.

Low-dose exposure to CPF leads to accumulation of CPF in different body tissues including liver, brain, kidney, ovary and adipose tissue. CPF induced damage in these tissues by lipid peroxidation and oxidative stress. MDA and NO are released by the damaged lipids and proteins. CPF releases free radicles (hydroxyl radicals), which react with unsaturated fatty acids in the brain, ovary and other body tissues of rats leading to damage of these organs. This process is called lipid peroxidation and results in the release of MDA and NO. GSH, CAT and SOD are endogenous antioxidants that protect against free radicles released by CPF (Tanvir et al., 2016).

Correspondingly, a progressive dosedependent increase in MDA levels was reported in CPF-treated rats. Treatment with CPF $10 \mathrm{mg} / \mathrm{kg}$ body weight increased MDA levels to $37.4 \mathrm{nmol} / \mathrm{ml}$ after 14 days and 35 $\mathrm{nmol} / \mathrm{ml}$ after 21 days. While, treatment with CPF $20 \mathrm{mg} / \mathrm{kg}$ body weight increased MDA levels to $38.74 \mathrm{nmol} / \mathrm{ml}$ after 14 days and 67.5 $\mathrm{nmol} / \mathrm{ml}$ after 21 days. This was minimized to 
$35.26 \mathrm{nmol} / \mathrm{ml}$ and $46.112 \mathrm{nmol} / \mathrm{ml}$ by the administration of curcumin and crude respectively (Madhavi and Sai Saraswathi, 2011). It was also reported that CPF increased MDA levels and decreased CAT and SOD activities in the pituitary gland of rats (Umosen et al., 2012; Muftau et al., 2014). A reduction in GSH levels (an antioxidant in tissues) was also reported in brain, ovary and uterus of rats (Uzun and Kalender, 2013; Adedara et al., 2017).

Abolaji et al. (2017) found that Ginger (6-GRF) protected against the peroxidative effects of CPF and rendered MDA levels to normal control levels. In addition, 6-GRF improved the levels of GSH in brain, ovary and uterus of rats.

Similarly, significant increased MDA levels were reported in the ovaries and thyroid gland of CPF-treated rats compared to the control group. However, concomitant treatment of CPF and PLO lead to a significant reduction in MDA levels compared to rats treated with CPF alone. In addition, there was a significant reduction in GSH levels in ovaries and thyroid of CPF-treated rats compared to controls. This was improved by the combined treatment of CPF and PLO (Chebab et al., 2017). Correspondingly, in vitro studies revealed that EGCG increased the intracellular levels of GSH in oocytes (Wang et al., 2007; Huang et al., 2018).

The immune-histochemical results of this study demonstrated that after CPF administration, most normal Graafian follicles disappeared from the ovaries and only few decomposed follicles with abnormal structures were seen.

The combined treatment of CPF and EGCG allowed a few numbers of seminormal young Graafian follicles to develop. The oocyte showed very little degeneration with the persistence of the lateral positioning of the nucleus, and the presence of greasy gaps in the oocyte cytoplasm. In addition, there was a clear improvement in the granulosa cells divisive capacity. However, these changes did not arrive at the normal level.

Proliferating cell nuclear antigen (PCNA) is a non-histone protein that has an auxiliary role for DNA polymerase delta. PCNA expression has a direct relationship with mitotic activity, so it can be used, as an indication of cell proliferation. The result of this study also demonstrated that the number of proliferating cells in graafian follicles decreased significantly in CPF-treated group compared with the control group. In addition, in this study, the utilization of EGCG plus CPF increased significantly the number of proliferating cells in these follicles as compared to the CPF group. Thus, antioxidants such as EGCG can improve cells' antioxidant system and protect cells against oxidative stress. The decrease in cell proliferation due to CPF exposure confirmed that OPs through the production of free radicals and oxidative stress damage DNA. The natural response to DNA damage is the activation of checkpoints that stop the cell cycle and repair the damage, and cause aging or apoptosis (Carlson and Ehrich, 2008).

Nishi and Hundal (2013) observed that micrometrical analyses showed increased ovarian surface epithelium height, follicular diameter, and the frequency of follicular atresia. A disruption in estrous cycle with prolonged metestrus was developed on $\mathrm{CPF}$ administration in both the treated groups (CPF 0.1 and $2.5 \mathrm{mg} / \mathrm{kg}$ body weight/day for 8 weeks).

In the present study, the administration of EGCG, an antioxidant, was found beneficial in guarding against the toxicity effects of CPF on reproductive functions in rat ovaries. Correspondingly, Madhavi and Sai Saraswathi (2011) found that CPF treated group showed ruptured germinal epithelium with multiple nuclei and matured Graafian follicles with 
degenerated ovum. Corpus leutium cells were observed to be rudimentary. Unusual number of vacuolated spaces was observed in ovarian cortex. After curcumin treatment for seven days the ova were regenerating. In addition, administration of vitamin $\mathrm{E}$, an antioxidant, was found to protect against the suppressive effects of DZN on the proliferation of secondary and Graafian follicles (Sargazi et al., 2019).

Thus, it was suggested that the administration of antioxidants could protect against tissue damage-mediated by oxidative stress. In vitro studies revealed that antioxidants can improve oocytes maturation (Zhao et al., 2018). One of the most potent natural antioxidants is EGCG, which is found in high concentration in green tea and can be used as a useful treatment against the oxidative toxicity effects of insecticides such as CPF.

\section{Conclusion}

It can be concluded that CPF exposure is associated with oxidative damage and toxicity in rats. CPF can interfere with normal weight gain, ovarian development, induce reproductive hormones disruption and histopathological changes in the ovaries. These toxicity effects are mediated by oxidative stress mechanisms. EGCG in green tea is a natural antioxidant, which can reverse the oxidative damage induced by $\mathrm{CPF}$ in rat ovaries.

\section{Acknowledgment}

Sincere thanks and appreciation to staff members of the Forensic Medicine and Clinical Toxicology, Pharmacology, Histology Departments, Faculty of Medicine, Benha University, for their cooperation.

\section{Conflict of interest}

The authors declare no conflict of interest.

\section{References}

Abolaji, A.O.; Ojo, M. and Afolabi, T.T. (2017): "Protective properties of 6gingerol-rich fraction from Zingiber officinale (Ginger) on chlorpyrifosinduced oxidative damage and inflammation in the brain, ovary and uterus of rats." Chem Biol Interact.;270:15-23.

Adedara, I.A.; Abolaji, A.O. and Idris, U.F. (2017): Neuroprotective influence of taurine on fluoride-induced biochemical and 663 behavioral deficits in rats." Chem Biol Interact.; 1-10.

Anckaert, E.; Mees, M.; Schiettecatte, J.; et al. (2002): "Clinical validation of a fully automated $17 \beta$-estradiol and progesterone assay (VIDAS $®$ ) for use in monitoring assisted reproduction treatment." Clin. Chem. Lab. Med.; 40 (8): 824-831.

Anirudhan, T. S. and Alexander, S. (2013): "Synthesis and characterization of vinylfunctionalized multiwalled carbon nanotubes based molecular imprinted polymer for the separation of chlorpyrifos from aqueous solutions." J. Chem. Technol. Biotechnol., 88 (10): 1847-1858.

Attia, A.A.; Elmazoudy, R.H. and ElShenawy, N.S. (2012): "Antioxidant role of propolis extract against oxidative damage of testicular tissue induced by insecticide chlorpyrifos in rats." Pest. Biochem. Physiol. 103: 87-93.

Bancroi, J. and Gamble, M. (2002): Heory and Practice of Histological Techniques. 
( $5^{\text {th }}$ edn) Churchil Livingstone, London, 231.

Bitzer, Z.T.; Elias, R.J.; Vijay-Kumar, et al., (2016): "(-)-Epigallocatechin-3gallate decreases colonic inflammation and permeability in a mouse model of colitis but reduces macronutrient digestion and exacerbates weight loss." Mol. Nutr. Food Res. 60: 2267-2274, https://doi.org/10.1002/mnfr.201501042

Carlson, K. and Ehrich, M. (2008): "Distribution of SH-SY5Y human neuroblastoma cells in the cell cycle following exposure to organophosphorus compounds." J. Biochem. Mol. Toxico.1., 22: 187-201.

Chebab, S.; Mekircha, F. and Leghouchi, E. (2017): "Potential protective effect of Pistacia lentiscus oil against chlorpyrifos-induced hormonal changes and oxidative damage in ovaries and thyroid of female rats." Biomed. Pharmacother., 96:1310-1316.

Clairborne, A. (1995): Catalase activity. In: R.A. Greewald (ed), Handbook of methods for 609 oxygen radical research. CRC Press, Boca Raton, FL. p.p. $237-242$.

Das, K.; Sarkar, K. and Nath, P.P. (2017): "Chlorpyrifos impairs the contraction of uterine smooth muscle by inhibiting the secretion of estradiol from ovary in rat." Int J Cur Res Rev.;9 (16 ): 43-48.

Das, K.; Sarkar, K. and Tarafder, P. (2014): "Chlorpyrifos suppresses female reproductive function in rat." Int. J. Pharma Bio Sci.; 5 (1): 810-818.

Fang, H.; Xiang, Y.Q.; Hao, Y.J.; et al. (2008): "Fungal degradation of chlorpyrifos by Verticillium sp. DSP in pure cultures and its use in bioremediation of contaminated soil and pakchoi." Int. Biodeterior. Biodegrad.; 61 (4): 294-303.
Gao, Z.; Han, Y.; Hu, Y.; et al. (2016): "Targeting HO-1 by Epigallocatechin-3gallate reduces contrast-induced renal injury via anti-oxidative stress and antiinflammation pathways." PLoS ONE 11, e0149032, https://doi.org/10.1371/journal.pone.0149 032

Hernandez, A. F.; Parron, T. and Tsatsakis, A. M. (2013): "Toxic effects of pesticide mixtures at a molecular level: their relevance to human health." Toxicology.; 307: 136-45.

Hodgson, E. and Rose, R.L. (2008): "Metabolic interactions of agrochemicals in humans." Pest Mang Sci.; 64(6): 61721.

Huang, Z.; Pang, Y. and Hao, H. (2018): "Effects of epigallocatechin3-gallate on bovine oocytes matured in vitro." AsianAustralas J. Anim. Sci.; 31: 1420.

Iheanacho, J.U.I.; Onyeka, P.I.K.; Udujih, H.I.; et al. (2020): "Sub-lethal study of Organophosphorus (chlorpyrifos) toxicity on reproductive biomarkers in female wistar rats." Int. J. Health, Safety and Environ.; 6 (02): 499 - 505.

Intra, J. and Kuo, S.M. (2007): "Physiological levels of tea catechins increase cellular lipid antioxidant activity of vitamin $\mathrm{C}$ and vitamin $\mathrm{E}$ in human intestinal caco-2 cells." Chem. Biol. Interact.; 169, 91-99. https://doi.org/10.1016/j.cbi.2007.05.007

Johari, H.; Shariati, M. and Abbasi, S. (2010): "The effects of diazinon on pituitary-gonad axis and ovarian histological changes in rats." Iran, J. Reprod. Med.; 8 (3): 125-130.

Jollow, D.J.; Mitchell, J.R. and Zampaglione, N. (1974): "Bromobenzene induced liver necrosis: protective role of glutathione and evidence for 3,4- 
bromobenzene oxide as the hepatotoxic metabolite." Pharmacology; 74:151-169.

Kamalesh, D.; Kaushik, S. and Panchali, T. (2014): "Chlorpyrifos suppresses female reproductive function in rat." Int $\mathrm{J}$ Pharm Bio Sci.; 5(1): 810-818.

Kerr, J.B.; Duckett, R.; Myers, M.; et al. (2006): "Quantification of healthy follicles in the neonatal and adult mouse ovary: evidence for maintenance of primordial follicle supply." Reproduction.; 132: 95-109.

Kiernan, J.A. (2001): Histologic and histochemical methods: theory and practice. 3rd edn., Arnold publisher, London, New York \& New Delhi p.p. 111-162.

Li, J.; Ren, F. and Li, Y. (2019): "Chlorpyrifos induces metabolic disruption by altering levels of reproductive hormones." J. Agric. food chem.;67(38):10553-10562.

Liang, Y.; Zhan, J. and Liu, D. (2019): "Organophosphorus pesticide chlorpyrifos intake promotes obesity and insulin resistance through impacting gut and gut microbiota." Microbiome.; 7 (1): 19 .

Madhavi, K. and Sai Saraswathi, V. (2011): "In vivo toxicological evaluation of chlorprifos pesticide on female albino mice: therapeutic effects of curcuma longa.” Int J Pharm Sci Res.; 2(2): 439447.

Mansour, S.A. and Mossa, A.T.H. (2009): "Lipid peroxidation and oxidative stress in rat erythrocytes induced by chlorpyrifos and the protective effect of zinc." Pestic. Biochem.; Physiol. 93 (1): 34-39.

Marklund, S. and Marklund, G. (1974): "Involvement of the superoxide anion radical in the autoxidation of pyrogallol and a convenient assay for superoxide dismutase." Eur J Biochem.; 47: 469-474.

Mavedati, O.; Bandariyan, E.; Aminashayeri, S.; et al. (2015): "ameliorates the reproductive toxicity of chlorpyrifos in male rabbit." Comp. Clin. Pathol.; 24 (2): 409-415.

Mihara, M. and Uchiyama, M. (1978): "Determination of malonaldehyde precursor in tissues by thiobarbituric acid test." Anal. Biochem.; 86: 271- 278.

Min, K.J. and Kwon, T.K. (2014): "Anticancer effects and molecular mechanisms of epigallocatechin-3gallate." Integr. Med. Res.; 3: 16-24, https://doi.org/10.1016/j.imr.2013.12.001

Muftau, S.; Aisha, O. O. and Ambali, S. F. (2014): "Ameliorative effect of hibiscus sabdariffa linn on subchronic chlorpyrifos-induced alterations in sex and thyroid hormones in male wistar rats." Am. J. Pharmacol. Toxicol.; 9 (1): 96-106.

Nishi, K. and Hundal, S.S. (2013): "Chlorpyrifos induced toxicity in reproductive organs of female Wistar rats." Food Chem. Toxicol.; 62: 732-738.

Ohno, A.; Kataoka, S.; Ishii, Y.; et al. (2013): "Evaluation of Camellia sinensis catechins as a swine antimicrobial feed additive that does not cause antibiotic resistance." Microbes Environ.; 28: 8186 , https://doi.org/10.1264/jsme2.ME12137

Picard, M.; Rossier, C.; Papasouliotis, O.; et al. (2008): "Bioequivalence of recombinant human FSH and recombinant human $\mathrm{LH}$ in a fixed 2:1 combination: two phase I, randomised, crossover studies." Curr. Med. Res. Opin.; 24 (4): 1199-1208.

Poet, T. S.; Timchalk, C.; Hotchkiss, J. A.; et al. (2014): "Chlorpyrifos PBPK/PD model for multiple routes of exposure." Xenobiotica.; 44 (10): 868-881. 
Pohl, F. and Kong Thoo Lin, P. (2018): "The potential use of plant natural products and plant extracts with antioxidant properties for the prevention / treatment of neurodegenerative diseases: in vitro, in vivo and clinical trials." Molecules.; 23 (12): 3283.

Rains, T.M.; Agarwal, S. and Maki, K.C. (2011): "Antiobesity effects of green tea catechins: a mechanistic review." J Nutr Biochem.; 22(1): 1-7.

Sargazi, Z.; Reza Nikravesh, M. and Jalali, M. (2019): "The protective effect of vitamin $E$ on rats' ovarian follicles following an administration of diazinon: An experimental study." Int J Reprod Biomed (Yazd).;17(2):79-88.

Sastry, K.; Moudgal, R.; Mohan, J.; et al. (2002): "Spectrophotometric determination of serum nitrite and nitrate by copper-cadmium alloy." Anal Biochem.; 306: 79-82.

Shady, A.M. and Noor El-Deen, F.I. (2010): "Effect of chlorpyrifos on thyroid gland of adult male Albino rats." Egypt. J. Histol. 33 (3): 441-450.

Sharma, S.; Singh, P.B.; Chadha, P.; et al. (2017): "Chlorpyrifos pollution: its effect on brain acetylcholinesterase activity in rat and treatment of polluted soil by indigenous Pseudomonas sp. Environ." Sci. Pollut. Res. Int.; 24 (1): 381-387.

Stata Corp. (2009): Stata Statistical Software: Release 11. College Station, TX: Stata Corp LP.

Takagaki, A.; Otani, S. and Nanjo, F. (2011): "Antioxidative activity of microbial metabolites of (-)epigallocatechin gallate produced in rat intestines." Biosci. Biotechnol. Biochem.; 75: 582-585, https://doi.org/10.1271/bbb.100683.
Tanvir, E.M.; Afroz, R. and Chowdhury, M.A.Z. (2016): "A model of chlorpyrifos distribution and its biochemical effects on the liver and kidneys of rats." Hum. Exp. Toxicol.; 35 (9): 991-1004.

Umosen, A.J.; Ambali, S.F.; Ayo, J.O.; et al. (2012): "Alleviating effects of melatonin on oxidative changes in the testes and pituitary glands evoked by subacute chlorpyrifos administration in Wistar rats, Asian Pac.” J. Trop. Biomed. 2 (8): 645650.

Uzun, F.G. and Kalender, Y. (2013): "Chlorpyrifos induced hepatotoxic and hematologic changes in rats: The role of quercetin and catechin." Food Chem. Toxicol.; 55: 549-556.

Ventura, C.; Nieto, M. R. and Bourguignon, N. (2016): "Pesticide chlorpyrifos acts as an endocrine disruptor in adult rats causing changes in mammary gland and hormonal balance." J. Steroid Biochem. Mol. Biol." 156: 1-9.

Wang, X.; Shen, M. and Zhou, J. (2019): "Chlorpyrifos disturbs hepatic metabolism associated with oxidative stress and gut microbiota dysbiosis in adult zebrafish." Comp. Biochem. Physiol., Part C: Toxicol. Pharmacol.; 216: 19-28.

Wang, Z-g.; Yu, S-d. and Xu, Z-r. (2007): "Improvement in bovine embryo production in vitro by treatment with green tea polyphenols during in vitro maturation of oocytes." Anim. Reprod. Sci.; 100: 22-31.

Weisburger, J.H. and Chung, F.L. (2002): "Mechanisms of chronic disease causation by nutritional factors and tobacco products and their prevention by tea polyphenols." Food Chem Toxical.; 40(8): 1145-54.

Wu, D.; Wang, J.; Pae, M.; et al., (2012): "Green tea EGCG, T cells and $\mathrm{T}$ cell- 
mediated autoimmune diseases." Mol. Aspects Med.; 33: 107-118, https://doi.org/10.1016/j.mam.2011.10.0 01

Yadav, M.; Shukla, A.K.; Srivastva, N.; et al. (2016): "Utilization of microbial community potential for removal of chlorpyrifos: a review." Crit. Rev. Biotechnol.; 36 (4): 727-742.

You, H.; Wei, L.; Sun, W.L.; et al. (2014): "The green tea extract epigallocatechin3-gallate inhibits irradiation-induced pulmonary fibrosis in adult rats." Int $\mathrm{J}$
Mol Med.; 34(1):92-102. doi:10.3892/ijmm.2014.1745

Zhang, Q.; Zheng, S. and Wang, S. (2019): "Chlorpyrifos induced oxidative stress to promote apoptosis and autophagy through the regulation of miR-19a-AMPK axis in common carp." Fish Shellfish Immunol.; 93: 1093 .

Zhao, X.M.; Wang, N.; Hao, H.S.; et al. (2018): "Melatonin improves the fertilization capacity and developmental ability of bovine oocytes by regulating cytoplasmic maturation events." J. Pineal Res.; 64: e12445. 


\title{
الآثار التحسينية لبوليفينول الشاي الأخضر Epigallocatechin-3- gallate على سمية الكلوربيريفوس على مبايض الفئران البيضاي البالغة
}

\author{
أمينة أ فرج' ، نشوى حسن أبورية"، ، أريج أدسوقى" ، هناء السيل عبد الرحمن بيومي؛ \\ ' ق قسم الطب الثرعى و السموم الاكلينيكية، كلية الطب، جامعة بنها

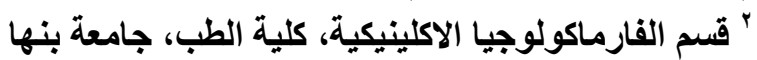

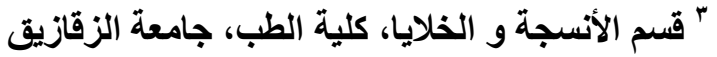

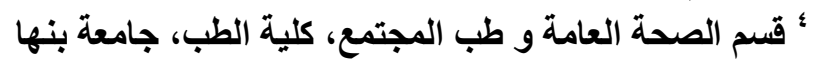

يمكن أن يسبب الكلوربيريفوس (CPF) تلف المبايض و خلل في الوظائف التتاسلية من خـلال آليات

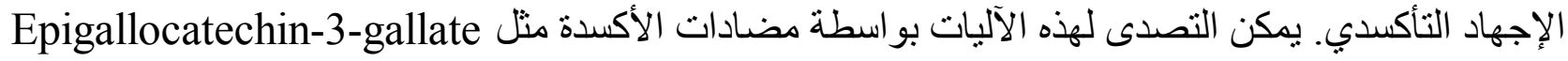
الموجودة فى الثابي الأخضر. هدفت هذه الدر اسة إلى التحقق من الآثار السمية للكلوربيريفوس على الآلى

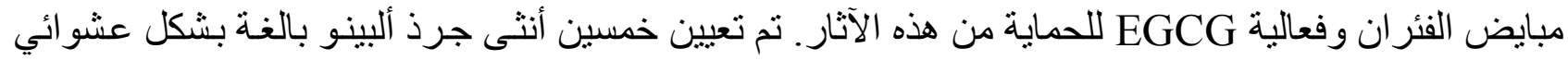

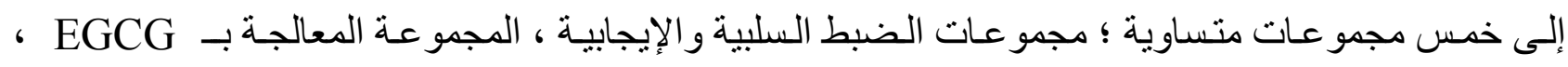

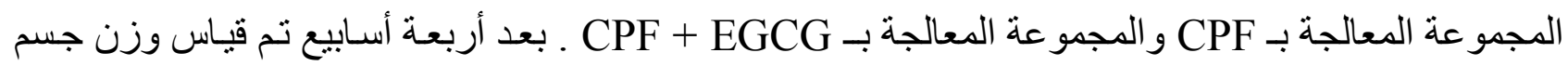

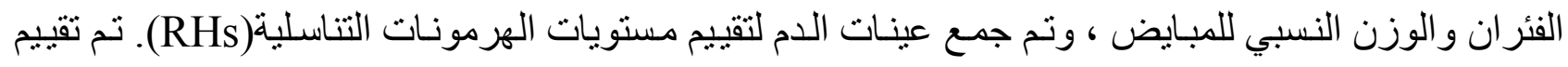

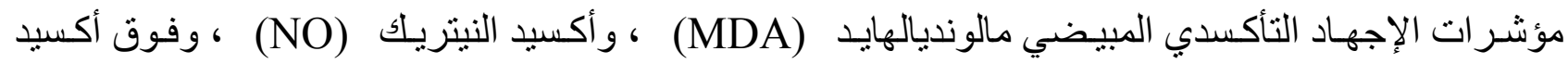

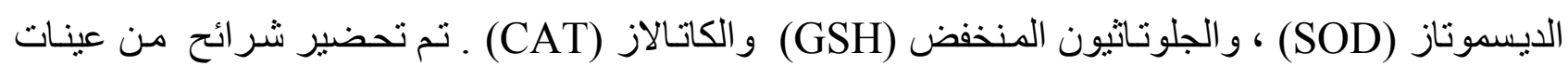

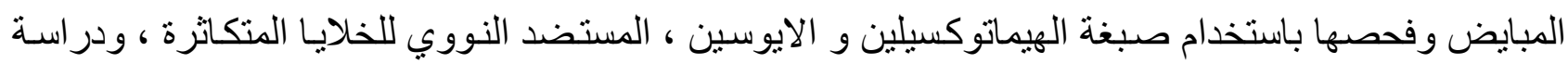

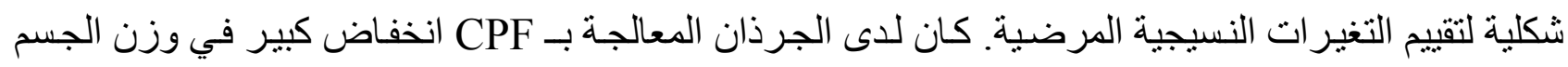

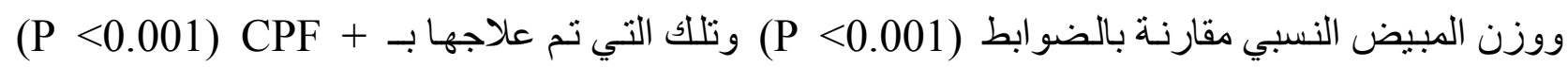

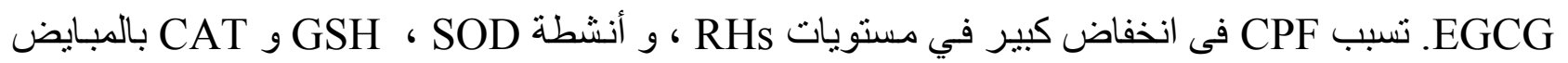

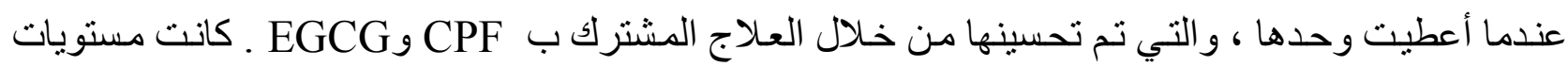

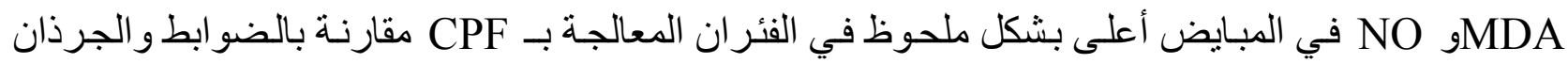

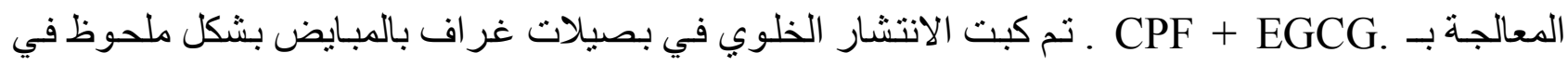

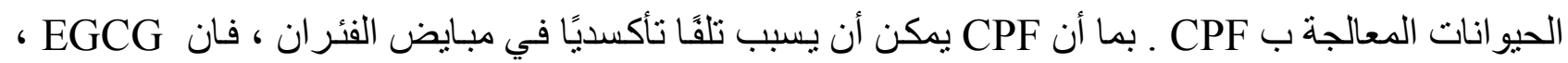

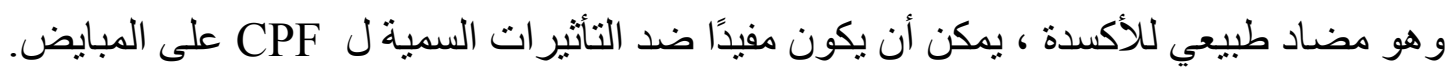

